\section{CO-OPERATION IN THE WAR AGAINST DISEASE}

\section{By SIR PHILIP MANSON-BAHR, C.M.G.}

$\mathrm{T}$ HE modern statesman is inclined to reject the terms of narrow nationalism, both in commerce and policy. $\mathrm{He}$ maintains his faith in the development, for the public good, of such co-operation and good-will which cannot be compatible with international mistrust and concealment. $\mathrm{He}$ is impelled to adopt this view, it is hoped, by the ideals of humanitarianism no less than by logic which implies search for efficiency. Yet it is self-evident that at present, without a radical change in method of government, which would go beyond political imagination, the control of geographical areas, or countries, must rest with the people of those areas. How far this control should be sovereign is a matter for debate; but there is little doubt that, in the matter of transmissible disease, the safety of the whole world community ought to take precedence over the rights of any particular people. In this respect there is one subject into which political considerations do not intrude and that is the advisability of a united, co-ordinated policy in the war against disease. This stands for the communal good. It is therefore opportune to formulate some ideas how such a campaign may be conducted. The causes of the main tropical and subtropical diseases are now well known, their conveyance to man and their effective treatments accurately ascertained. A proviso should here be made that the diseases, so named, may also be important in temperate lands. To illustrate this point, reference may be made to certain of these diseases and to some of the reasons which compel international attention. In this article, certain problems will be briefly stated and certain lines indicated which appear indispensable to their solution.

Malaria is perhaps the commonest disease in the world ; it takes a heavy toll of infant life and causes more incapacity than most people realize. But it is not a static disease; it may, from time to time, appear in epidemic form and as such spread over international boundaries. To understand this it is necessary to comprehend something of the modes of spread of this disease, which is a complex partnership between the parasite, the mosquito, and man.

The cause of malaria is, of course, the malaria parasite, of which four species are recognized in man; they differ from each other in appearance and in their effects. The most dangerous is undoubtedly the malignant tertian parasite, which is particularly tropical in its distribution - though found as far north as Italy, Greece and Rumania - and which is the essential cause of the much-dreaded blackwater fever, a sequel which has cost the lives of so many Europeans in Africa and elsewhere.

The limited range of this parasite is explained by the ascertained fact that it requires a higher atmospheric mean temperature to complete its development inside the mosquito. It is one of those unexplained, and at present almost inexplicable, facts of biology that only mosquitoes of the genus Anopheles have been proved capable of transmitting malaria from man to man. In members of this genus the malaria parasite undergoes an essential stage of development before it is capable of once more infecting man; but for the essential points in the present argument it is necessary to realize that not every member of the genus Anopheles is able to transmit malaria; that of those species which can do so, some are highly effective and others less so; that their effectiveness depends largely on the degree to which a species seeks human blood rather than that of animals, and that the effective spread of malaria depends upon the ability of efficient carrier mosquitoes to herd in close association with man.

Of efficient carriers there are at least six in Africa and many more in Asia. For breeding, some species need water open to the sun, others demand shade; some need relatively high temperatures, others prefer cool waters; some even require barackish water which is prohibitive to others; some need clear, limpid streams, others will breed in a muddy water-filled hoof-print. Then different species of Anopheles have characters which are relatively constant and are therefore vitally important. Thus a locality may be infested with Anopheles and yet have no malaria, but a change in agricultural habits of the people, for example, introduction of artificial irrigation, may so modify the composition or condition of the water that Anopheles of dangerous species, present in contiguous areas, may infiltrate, to initiate an epidemic of malaria in a population devoid of immunity.

In other circumstances the water may be suitable to the breeding of Anopheles; but these mosquitoes may not be present. If in such cases they are introduced, and, if persons carrying the malaria parasite in their blood exist in sufficient numbers, then con. ditions for epidemic transmission will have been created. This is the present position in certain groups of islands in the Pacific. Anopheles are not yet there, but may well be introduced in ships or in aircraft from other lands.

Again, malaria may be present, but the local Ano. pheles may be a relatively poor transmitter, so that the disease is maintained at a low rate of incidence; but if to such a community a vigorously breeding, manloving Anopheles is introduced, the result may be an epidemic of malaria lasting many years, in which the human death-roll may amount to tens of thousands. This is not speculation, but is exactly what happened to Brazil about 1930, when that most versatile malaria-carrier, Anopheles gambice, was transported from West Africa to Brazil in the fast steamers which ran between Dakar and Natal (a port in Brazil), became established there and earried death and ruin to a large peasant population for ten years. At the cost of enormous exertion, this mosquito has at last been eradicated from Brazil by the combined efforts of the Government and the Rockefeller Foundation, and the epidemic has ceased; but though the organization which made this great feat possible was brilliantly conceived and should serve as a model for the world, the tragic episode underlines the overwhelming truth of the old adage that prevention is better than cure; and prevention would be difficult without co-operation between sovereign States-between the country from which the mosquito originated and that to which it travelled. Prevention demands, for example, that no mosquito which may enter an aircraft at an aerodrome in West Africa should be allowed to escape on arrival in Brazil - the authorities at each end must take their complex precautions. Moreover, the work of eradication of Anopheles gambice from Brazil was assisted 
by -note the title - the International Health Division of the Rockefeller Foundation. India also has its own malaria.problems; but India knows no Anopheles so vicious as Anopheles gambice, and it is conceivable that this mosquito, to which West Africa owes most of its evil health reputation, might be taken by aircraft to India, there to repeat its Brazilian feat. Thus the rapidity of modern travel has raised problems previously unknown.

It is therefore clear that prevention of malaria on an international scale entails the close co-operation of specialists in many directions. It demands the mutual understanding between doctors, entomologists, agriculturists and irrigation engineers; without this an individual alone is helpless. The medical entomologist is there to identify the Anopheles, to detect its breeding places and to direct methods for its eradication. To give some idea of the technicalities involved it has to be pointed out that there are variations even in one species which are of great importance. Thus Anopheles maculipennis, the chief transmitter in Europe and North Africa, is divisible into no less than seven races in the Old World and one in the New, which can be distinguished from one another (like birds) by the colour pattern of their eggs. Some are important species in the present sense : others not at all.

What is true of malaria bears a definite relation to another great mosquito-borne disease-yellow fever. "Yellow Jack" once destroyed one of Napoleon's armies in the West Indies and frustrated the French attempts to force a canal through Panama until finally defeated by the Americans under General Gorgas; it was the terror of Caribbean sailors and West African traders; the pernicious and deadly joundice which gives it its name was the origin of the yellow colour long ago adopted, and still maintained, for the quarantine flag. Yellow fever is caused by an ultra-microscopic virus, a group of organisms the members of which include the causes of measles, influenza, smallpox and numerous plant diseases, and this virus is transmitted from the blood of infected man to that of a healthy individual by mosquitoes during the act of biting. Unlike human malaria, yellow fever is a disease which affects certain wild animals, particularly South American monkeys, opossums, which constitute a reservoir of disease that must be taken into account, and it is transmitted chiefly by mosquitoes of the genus $A \ddot{e} d e s$, of which the most important is the semi-domestic species-- the tiger mosquito-Aëdes oegypti.

These mosquitoes are abundant throughout the tropics, in America, Africa and Asia; but yellow fever has fortunately not hitherto been known in Asia and Australia. Should the virus be introduced there, the stage would indeed be set for an epidemic the like of which has, perhaps, not yet been known, and although there is a vaccine which, when inoculated, affords excellent protection, inoculation of the millions of people in India and the Far East would be such a gigantic task that it is preferable to take the most extensive and radical measures to prevent the entry of this disease.

But an infected mosquito might enter an aeroplane in Africa and escape from it in India, might infect a villager who in turn might infect a dozen local $A \ddot{d e d e s,}$ and so on. Or, again, a man in Africa might travel by air to India during the incubation period of the disease before recognizable symptoms develop, on arrival the disease might not be readily diagnosed, and in the interval he might easily infect local Indian
Aëdes argypti. All this is, of course, well recognized, and active precautions are being taken to guard against such happenings; but it is by no means easy to realize how detailed and how fine must be the system which attempts (so far with success) to protect the East against yellow fever. One crucial point in this protective system is international co-operation. Each threatened country must take its own precautions, but each already infected country has a responsibility to ensure that aeroplanes departing from its aerodromes do not carry with them infective material, human or otherwise. International conventions have indicated how these responsibilities should be met.

African trypanosomiasis (sleeping sickness) has for centuries played havoc with the natives of that disease-ridden continent, but as yet this affliction is confined to Africa. It is caused by a tiny protozoon in the blood, which is picked out and transmitted, in the act of biting, by tsetse flies. It is, again, one of the unexplained mysteries of biology why this organism is so selective that it cannot be transmitted by mosquitoes (apart from occasional mechanical transmission by certain other biting flies), and that it cannot undergo its essential development in insects other than the tsetse; yet the fact remains.

In the days of slave trading, negroes suffering from sleeping sickness were often transported to the West Indies. They died there of the disease, yet sleeping sickness was never established in the western hemisphere, because the requisite flies did not exist there. The tsetse is a land fly, it does not frequent harbours, it has no incentive to get aboard ship; but it does seek shade, and may be attracted to the shade' of an aeroplane standing near a patch of trees on an aerodrome; it may enter the aeroplane and travel with it, and if living infected flies were to reach parts of America and become established there, there is little doubt that the disease would be propagated: the danger is, perhaps, somewhat remote, but the discovery of dead tsetse flies in aircraft arriving in Brazil has been regarded as something of an omen by the South American authorities.

These three diseases illustrate the fact that in warm climates some of the major dangers to health are transmitted from man to man, or from animals to man, by flying insects. But there are great epidemic diseases, conveniently labelled tropical because their present incidence is mainly in hot countries, which are, in fact, diseases of all climates and which are' transmitted by arthropods which do not fly.

Plague was more than once rampant in Englandthe Black Death and the Great Plague were instances of spreading epidemics-and is now present in the rodents of the United States, as well as of Africa and Asia. It is essentially a disease of rats and field rodents, and is spread among them by their fleas. Fleas leave dead animals, and in default of living rodents on which to feed, will attack man. The cause of plague is a bacillus which is present in the blood of a diseased animal, and which is taken up by the flea when it feeds. In the flea it multiplies, and, in certain circumstances, may be injected into another animal (or man) at a subsequent foed. There is thus the cycle rat-flea-rat, and if the mortality among rats is high, and the chance of feeding on rats consequently low, and if the rat community is in close association with man, there is a spill-over of plague to man, which, in extreme conditions, may be of 
great proportions, with devastating epidemics. Rats, of course, seek food which is to be found especially near human habitation, or in food stores, in bazaars of the East, and in ships. They are great climbers; and a dock area heavily infested will, unless transit is prevented, both give to and receive from incoming ships considerable numbers of rats. An infected rat may invade a ship, start the disease in the ship's rats, and an infected rat may leave the ship at another port, infect the rats of that port, and originate an epidemic in man. This course of events has happened often in the past and the danger is always present. There has recently been an. outbreak in Haifa and Jaffa; the rats of Rangoon and Hawaii have been infected for many years; human deaths from plague are constantly reported from Istanbul; in India, Java, and Madagascar plague in man is constantly present.

Plague, therefore, is a disease which is peculiarly associated with commerce and trade routes, with ports and shipping. These are pre-eminently the international links, and it is just here that control measures must be, and indeed are, co-ordinated by international agreements.

Typhus, which Zinsser regarded as a more potent arbiter of the fate of nations than the Caesars or Napoleons of history, is transmitted from man to man by the louse. It is caused by a minute organism which is taken in by the louse when it feeds. Typhus flourishes when lice flourish, in cold weather when clothing is not often removed, and particularly when social life is disorganized by war, with its masses of refugees herded together and without the means of cleanliness, or in famine, when the people flock to the great cities and live in crowded conditions, as in North Africa. Typhus killed more people than all the weapons of war in 1914-20 ; in the present War the great attention given to it by the Germans indicated a prevalence they were not anxious to admit. In North Africa the incidence has been heavy during the last few years ; in China the refugees from invasion were heavily diseased; in Spain a violent epidemic followed the civil war. The introduction of typhus into a crowded community, which is already infected with the necessary lice, may produce the final condition needed for an outbreak.

Those diseases which are not specifically insectborne present problems not less complex and not less urgent. Cholera may be introduced into a country by the movements of labourers, by pilgrims or by refugees from war ; smallpox has many times invaded tropical countries in the same way; the common fevers of childhood, such as measles, at one time played havoc in Fiji, where the natives had no immunity, and the same course of events has recently been enacted in remote villages traversed by the newly built Alaskan highway. The same thread runs through these happenings : the introduction into one area of diseases prevalent in another, across national boundaries.

Moreover, there are less spectacular diseases, such as tuberculosis, leprosy, venereal diseases, yaws, hookworm infection, unevenly spread over the tropics but affecting grossly the health and happiness of enormous communities, and their eradication could not satisfactorily be undertaken by the uncorrelated actions of individual States. These are the responsibilities of Governments, but the resources of some of the tropical countries are totally inadequate to their needs. At the root of much of this chronic illness is the poor state of nutrition of the people, the poor state of agricultural knowledge and equipment and the low state of general hygiene.

The science of nutrition is still in its infancy. This sounds a queer statement, as the desire for food and the adequate nutrition of the body is surely a primitive instinct. So it comes as a rude awakening to realize that lack of proper ingxedients in the diet is at the root of most human evils. Just as weeds will grow and flourish on poor soil, so will the germs of disease when the defence mechanisms of the human frame are weakened by insufficient nutriment.

It has now been established beyond doubt that the majority of tropical peoples are existing on grossly insufficient foods. This is especially the case in the West Indies, Central Africa and China. There the native foodstuffs do not provide the necessary amount of proteins and fats. Some tribes are under. nourished because they do not eat meat or drink milk, even when they are at hand. There are taboos, traditions and beliefs-all so ingrained that it may take centuries of education to eradicate them. There can be no reasonable doubt also that wrong feeding is one of the principal causes of the very high infant mortality in most tropical countries.

The main facts are summarized in the two reports of the Economic Advisory Council on Nutrition in the Colonial Empire published in 1939. A study of this mass of information makes illuminating reading and strengthens the belief that the subject of nutrition is all-pervading and of the utmost importance. It is the ground rock of health and one which underlies the maintenance of virile and healthy populations. It strengthens the belief, if proof were needed, that if the soil of the body is defective, no medical skill or specific drug treatment can be effective in eliminating the seeds of disease.

The argument sustained by these facts is that the responsibility of the advanced countries to their own peoples demands that they should urge the less advanced to prevent the export of transmissible disease, as well as that they should themselves prevent its ingress. The less advanced must be persuaded to adopt those sanitary measures, those quarantine restrictions, that the community of nations considers necessary to general well-being. But the advanced have a human responsibility to the uninstructed peasant populations of other lands, which should not be estimated on a safety basis or on a cash value. Self-interest is not a policy that can appeal much to a world which wants a faith, and in medicine more than in any other human activity there is need for co-operation and the pooling of resources on the widest scale.

To be more precise, the Government of each nation must do its utmost for the health of its own people, must protect its own people from disease brought in from abroad, must ensure, so far as possible, that reasonable steps are taken to prevent the export of its own diseases, and must be prepared to place at the disposal of the rest of the world reports on its own health and swift news of any major epidernic outbreak. The last, indeed, has already been the rule on a large scale, and before the War the Far Eastern Bureau of the League of Nations at Singapore issued early warning of the great tropical epidemic diseases throughout its area. The Pan-American Sanitary Bureau, and the Paris International Office of Public Hygiene performed like functions. But these organizations were not world-wide; they were not complete, and the position cannot be satisfactory until completeness is achieved. 
Again to be precise, the controlling Governments of tropical Colonies must render to those Colonies services more regulated by their needs than by their capacity to pay. These services, in the matter of health, include education and research, equipment and personnel on a scale not often attempted, and embracing not only medicine but also agriculture, animal husbandry and industrial development. Moreover, it is a moral responsibility for the more advanced nations to lend to the less fortunate nations, without thought of reward, the services they need, even if those less fortunate peoples are self-governing.

Apart from good-will, high ideals and financial help, the essential basis for this co-operation between nations is knowledge. First, there is the knowledge of the outbreak of transmissible disease. This information must be given by the affected country to a central organization with the utmost speed and accuracy, so that spread to other countries may be prevented.

Second, there is the knowledge of the general state of health of these countries. Much of this can be, and in fact is, contained in official annual medical and health reports, but for many of the countries of the tropics such reports are difficult to obtain, or are not made. Any person interested in the health conditions of the British Crown Colonies, or of certain tropical dependencies of other nations, has at his disposal a satisfactory range of annual reports, but some other countries, of great importance to world health, do not offer this service.

Third, there is the knowledge of the complex problems of disease, which is being slowly and painfully acquired by research workers and investigation throughout the world. This knowledge is made available through the medical journals of all countries, which now make up a mass of literature so great, and in such a multiplicity of languages, that fow workers even in restricted subjects, and none in wider fields, can hope to read all that should interest them. Outstanding achievements soon receive universal recognition, but each outstanding discovery is followed by a mass of investigation which modifies and re-assesses its application and value. It is necessary that accounts of this work be assembled by some agency in a form convenient for those who, desiring to know of it, are unable themselves to perform the tedious task of searching the literature.

Apart from the international aspect of this problem, the British Empire has a definite responsibility towards the many peoples over whose welfare it presides. Promotion of medical knowledge and raising the standard of health in every portion of the globe is the best method of securing good-will and strengthening the machinery of government. Medical education is being extended on British lines in India, Ceylon, Africa and elsewhere. The needs of native medical schools and practitioners has to be catered for by the dissemination of knowledge. 'It is therefore eminently desirable that Great Britain should take an honourable place in the provision of medical information suitable to its world-wide responsibilities. To strive for such an ideal is surely not beyond the powers of a nation which has stood shoulder-square to the perils of the last five years of war.

I wish to express my indebtedness to Dr. Charles Wilcocks of the Bureau of Hygiene and Tropical Diseases for his helpful advice and assistance in the compilation of this article.

\section{AUTOSYNTHETIC MOLECULES}

\author{
BY DR. T. F. DIXON
}

$\mathrm{K}^{\mathrm{N}}$ NOWLEDGE of the mechanism of cellular protein synthesis has been advancing rapidly with the aid of the ultra-violet and electron microscopes. Nucleic acids show characteristic high absorption maxima at $260 \mathrm{~m} \mu$, due to the purine and pyrimidine constituents which distinguish them from other substances in biological material. By using the quartz microscope with monochromatic ultra-violet light, information has been obtained about the role of nucleic acid in cell division ${ }^{1}$ and the nucleoprotein nature of the chromosome and gene ${ }^{2,3}$. Indirect evidence for the latter has been obtained by ultraviolet irradiation of germinal tissue, when high efficiencies of mutation have been observed at $260 \mathrm{~m} \mu^{4}$. Viruses also appear to be nucleoproteins.

All animal and plant cell nuclei give positive Feulgen reactions, indicating the presence of desoxypentose, whereas pentose is characteristic of the cytoplasm. Variations occur not only in the sugar and pyrimidine components of the nucleic acid portion and its degree of polymerization, but also in the proportion and nature of the protein with which the nucleic acid is combined. Thus nuclear material from fish sperm heads (the classic example) contains approximately 2 parts of nucleic acid combined with 1 part of the strongly basic protein protamine; whereas in tobacco mosaic virus nucleoprotein 6 parts of nucleic acid are linked with 94 parts of a less basic and more complex protein. The nucleoproteins may form complexes with lipides. For example, the viruses of Rous sarcoma ${ }^{5}$, equine encephalomyelitis ${ }^{6}$ and the elementary bodies of vaccinia? have been shown to be associated with phospholipid-nucleoproteins.

The word virus has been applied mainly to agents residing in multicellular organisms; and when individual free-living cells are the hosts, such as bacteria, they are referred to as bacteriophages. The property of obligate parasitism or infectiousness has been found to be associated with certain high molecular weight nucleoproteins which are foreign to the host proteins and are probably the viruses themselves. In many cases one attack of a virus disease in an animal may produce a lasting immunity demonstrable by certain serological phenomena such as complement fixation, agglutination, precipitation and neutralization. Enduring immunity may depend on the kind of tissue infected and is probably due to a long-term sojourn or persistence throughout the life of the host. Lasting immunity may not be obtained to influenza or to the common cold virus because the superficial cells lining the respiratory tract are being thrown off at intervals to be replaced by deeper cells, and thus do not provide a permanent abode for these viruses. The fact that injection of immune or convalescent serum has little influence on the course of some virus diseases is not surprising when it is considered that the viruses are multiplying within the cells and may never be subjected to the action of humoral antibodies.

Certain cancerous growths are associated with viruses. Such growths are transplantable, and agents with which the disease can be produced again can be extracted from them. Thus viruses are responsible for tumours of the renal epithelium of frogs, for a 